\title{
Assessing solar and wind complementarity in Texas
}

\author{
Joanna H. Slusarewicz and Daniel S. Cohan ${ }^{*}$
}

\begin{abstract}
As wind and solar power installations proliferate, power grids will face new challenges in ensuring consistent coverage from variable renewable resources. One option to reduce variability is to integrate the output from wind and solar facilities with dissimilar temporal profiles of output. This study measured the complementarity of wind and solar resources sited in various regions of Texas. This study modeled solar and wind power output using the System Advisory Model with solar data from the National Solar Radiation Database and wind data from the Wind Integration National Dataset Toolkit. Half-hourly power production was assessed based on resource location, plant size, hourly load, inter-annual variability, and solar array design for all sites. We found that solar and wind resources exhibit complementary peaks in production on an annual and daily level and that West and South Texas wind resources also exhibit complementarity. Pairings of West Texas wind with solar power or South Texas wind sites yield the highest firm capacity. Solar farms are better suited for providing power during summertime hours of peak demand, whereas wind farms are better for winter. Taken together, our results suggest that Texas renewable power production can be made more reliable by combining resources of different types and locations.
\end{abstract}

Keywords: ERCOT, Electric reliability, Variable renewable energy, Firm capacity, Peak average capacity percentage, Wind and solar power siting

\section{Introduction}

Wind and solar power now provide the least-cost options for electricity generation in windy and sunny regions of the USA, even before accounting for subsidies and environmental impacts (Lazard 2017). Wind and solar also yield substantial benefits for climate, air quality, and health when replacing fossil fuels (Jacobson 2008). However, the variable nature of wind and solar power production limits their ability to displace fossil fuels. Aggregating multiple intermittent generators whose output differs temporally can reduce the uncertainty and variability of their output (Hart et al. 2012). Reduced intermittency can be achieved by aggregating multiple wind farms (Kahn 1979) or by combining the output of wind and solar farms (Zhou et al. 2010).

In 2017, wind provided $17 \%$ of power generation on the Electric Reliability Council of Texas (ERCOT) grid,

\footnotetext{
*Correspondence: cohan@rice.edu

Department of Civil and Environmental Engineering, Rice University, 6100 Main St. MS 519, Houston, TX 77005, USA
}

which covers most of Texas, while solar provided just $1 \%$ (ERCOT 2017a, b). Many analysts expect both of these sources could provide an increasing share of electricity as their costs have fallen (Lazard 2017) and as aging coalfired power plants close. In 2018 alone, four coal plants are closing in ERCOT. ERCOT provides a distinct testbed for analysis because it is relatively isolated from the interconnected power grids that supply electricity to most of North America.

The rapid evolution of generating resources in ERCOT raises the question of the extent to which variable output from solar and wind can replace the retiring coal. Since solar and wind power production vary with the weather, other sources or storage are needed to ensure power demand is fulfilled continuously.

One way to reduce the need for costly storage and for polluting fossil generation is to deploy wind and solar capacity in a way that minimizes the times when their power is unavailable. Previous studies have shown that in many areas solar and wind resources demonstrate anti-correlated peaks and valleys in intensity throughout 
the day (Monfortia et al. 2014). Alongside this natural resource complementarity at a given location, diversifying the locations of these resources is an important component of wind/solar complementarity (Prasad et al. 2007; Liu et al. 2013; Shaner et al. 2018). In addition, spreading out farms in certain regions results in an increase in the reliability of solar alone (LBNL 2009) and wind alone (Katzenstein et al. 2010). In particular, wind production in northwest Texas has been shown to increase as the area of distribution increases (Katzenstein et al. 2010).

Taking advantage of complementarily of wind and solar resources as well as the natural complementarity of systems with large spread can lead to a greater ability to meet consumer demand. Including both wind and solar in ERCOT's energy portfolio evens out production and reduces the number or hours where either resource cannot produce (Prasad et al. 2007). In addition, increasing the area over which wind and solar plants are located means that production times are less correlated, enhancing the performance of forecasts (Hart et al. 2012) that are crucial to power pricing and dispatch.

This study aims to identify locations and configurations of wind and solar facilities in ERCOT that would optimize the magnitude and complementarity of their power production. To do so, we analyze temporal patterns and variability in expected power production from potential wind and solar farms in Texas, using metrics developed in past studies for other regions together with metrics specifically targeted to ERCOT. This study pulls together multiple metrics from the literature and compares them to the operational metric used by ERCOT to determine the reliability of wind and solar. It takes these metrics and applies them to a new region, using data from the National Renewable Energy Lab (NREL) to model wind and solar farm output.

\section{Methods}

\section{Site selection}

Five wind sites and seven solar sites were selected throughout Texas (Fig. 1). These locations represent currently existing wind and solar farms, since the feasibility of placing resources at these sites has already been demonstrated. We separated wind sites into three West Texas (non-coastal) sites and two South Texas (coastal) sites, because the regions differ in the magnitudes and seasonal and diurnal patterns of wind speed. Specifically, West Texas winds are stronger and peak in the spring and at nighttime, whereas winds along the South Texas Gulf Coast tend to peak with summer afternoon sea breezes.

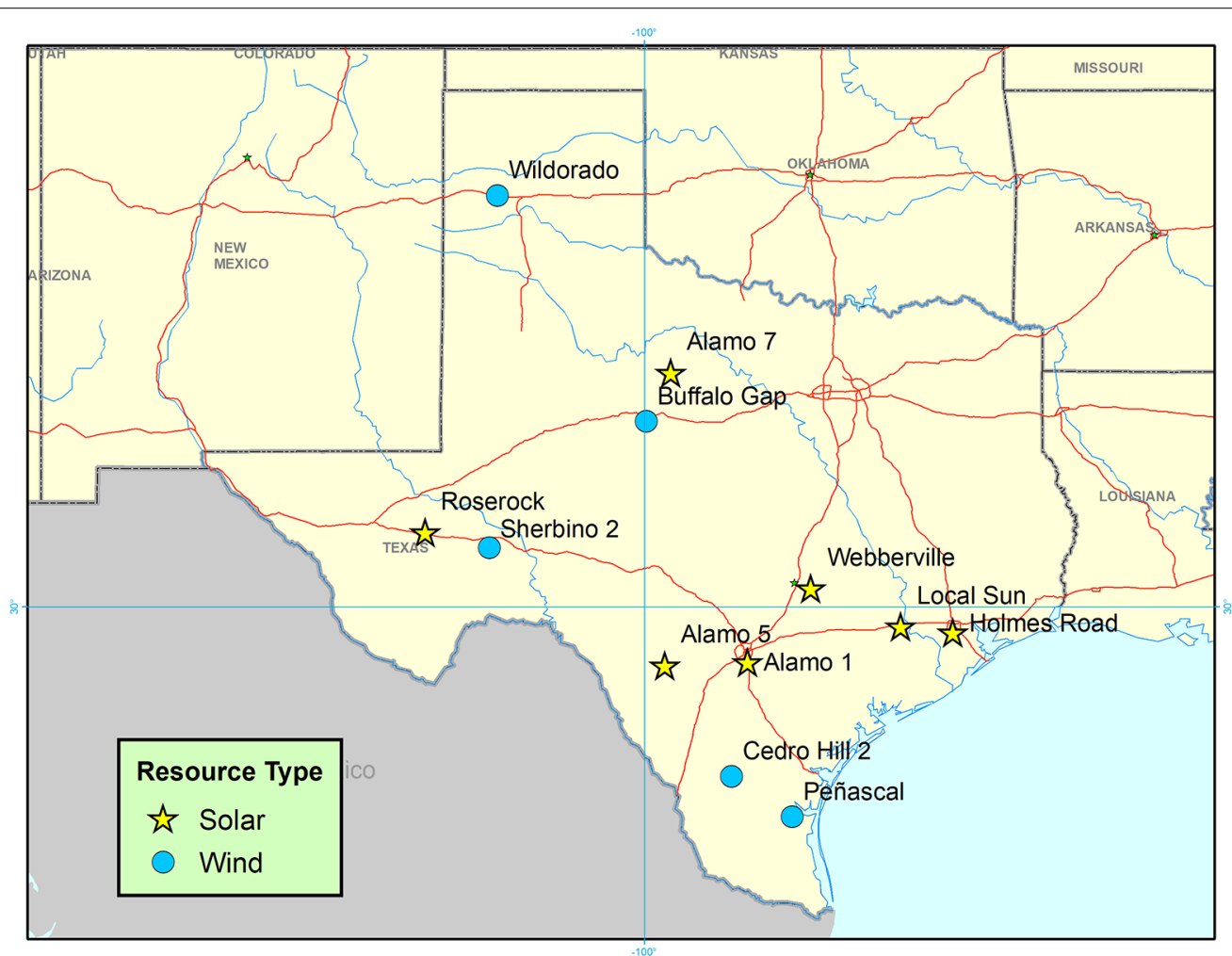

Fig. 1 The twelve sites selected for this study. Wildorado Ranch, Buffalo Gap, and Sherbino 2 are classified as "West Texas wind" and Cedro Hill 2 and Peñascal as "South Texas wind" locations 


\section{Solar data}

The National Solar Radiation Database (NSRDB) provided by the National Renewable Energy Laboratory (NREL) estimates weather conditions at any point in the USA using the Physical Solar Model (PSM). The model takes satellite data from the Geostationary Operational Environmental Satellites (GOES) as input and calculates projected global horizontal irradiance (GHI) from cloud properties (Sengupta et al. 2015). It is worth noting that the validation for the PSM provided by NREL overestimates model error, and corrected validations show that GHI estimates range from -2.6 to $4.0 \%$ bias compared to measured data (Yang 2018a, b).

Half-hourly PSM raw weather data were accessed for years 2007-2013, and NREL's System Advisor Model (SAM) was used to process these data into usable power outputs. We used 2012 as the base model year for calculations and considered the full 2007-2013 data for analyzing inter-annual variability and peak average capacity percentages. In conjunction with weather data from each of the seven selected solar sites, various solar array configurations were used as inputs to SAM to create modeled half-hourly power output throughout the year. As our base case, we assumed a $30 \mathrm{MW}$ DC farm with single-axis tracking because that is the most widely used configuration for utility-scale solar in the USA (Bolinger et al. 2017). Dual-axis and fixed-tilt systems were considered as sensitivity cases, since dual-axis has been used to boost output at some Texas farms and fixed-tilt provides the cheapest available option.

\section{Wind data}

Data were extracted from NREL's Wind Integration National Dataset (WIND) Toolkit to estimate power production for each of the five wind sites every 5 min during years 2007-2013. The WIND Toolkit modeled weather conditions using the Weather Research and Forecasting Model (WRF) model and then generated a 2-km-by$2-\mathrm{km}$ resolution grid of power production data for eight 2-MW, 100-m hub-height wind turbines (Draxl et al. 2015). For each of the five sites, this power production dataset was scaled to represent a 60-MW wind farm and the data were aggregated to half-hourly resolution for wind power output.

\section{Metrics for analysis}

Since the purpose of this study was to assess the complementarity of renewable resources across the sites, both the power production capabilities and the resource variability of pairs of sites were assessed. The goal was not only to maximize raw production, but to maximize reliable production by accounting for temporal synergy between different sites. To do this, metrics used in the analysis were grouped into three categories: total generation, which represents total power production regardless of timing; variability, which represents the fluctuations of power output over the year; and reliability, which combines capacity and variability to measure how much power can be relied upon to be available at least a certain percentage of the year. The statistical metrics used to assess these measures are described below.

\section{Metrics for total generation}

A widely used measure of a plant's generation output is capacity factor, which is the average power output over the maximum possible power output (the nameplate capacity) over a period of time. Facilities located at sites with strong wind or solar resources, or using best available technologies such as dual-axis tracking in the case of solar, will tend to have higher capacity factors.

\section{Metrics for variability}

Variability of power output was quantified by the coefficient of variance (COV; the ratio of the standard deviation to the mean). COV was computed based on half-hourly power output of a single site or the combined outputs of a pair of sites.

The Pearson correlation coefficient was used to assess the degree to which production rates of one resource supplement or complement the production of another. Negative coefficients indicate sites whose output is anticorrelated in time and hence complementary.

\section{Metrics for reliability}

Two metrics were identified in the literature to assess the reliability of power production: firm capacity and peak average capacity percentage.

For firm capacity, we adopt the approach of Archer and Jacobson (2007). They pointed out that coal-fired power plants are typically available $87.5 \%$ of the time, after accounting for scheduled maintenance and unscheduled maintenance or outages. Thus, they defined the firm capacity to be the 87.5 th percentile hourly capacity factor; in other words, the output that can be relied upon to be available at least $87.5 \%$ of the year. A visual explanation of this metric can be seen in Fig. 6, where the intersection of the duration curve and the vertical line represents the minimum amount of power produced in the top $87.5 \%$ of production hours.

Peak average capacity percentage (PACP) is defined by ERCOT (ERCOT 2018) as a facility's average capacity factor over the top 20 load (i.e., power demand) hours for the peak season (either summer or winter). When seasonal PACPs are calculated, all summer values and all winter values for years where weather data are available 
(up to 12 years) are averaged separately, resulting in a percentage that characterizes the resource's ability to satisfy summer and winter peak load. In this study, we used peak seasons from 2007 to 2013, the years for which weather data were available for the sites. The hours of peak load were determined based on hourly load data across the ERCOT grid.

\section{Results and discussion}

\section{Single site analyses}

Of the twelve locations selected for this study, the five wind sites exhibited the highest capacity factors in 20072013 (Fig. 2). The three West Texas wind sites each had higher capacity factors than the two South Texas wind sites. The capacity factors for the solar sites were lower and more similar across Texas. This in part results from the fact that potential wind power output varies with the cube of wind speed, while solar output varies linearly with solar irradiance.

Next, we computed the average PACP for each site from 2007 to 2013 to assess average outputs during peak load hours (Fig. 2). We compare our calculations of PACP with the factors used by ERCOT in its assessments of resource adequacy. There, ERCOT applies the following factors to wind and solar capacity when tallying their contributions to total resource adequacy: $14 \%$ non-coastal wind, 59\% coastal wind, and 75\% solar for summer resources (ERCOT 2018); and 20\%, 42\%, and $9.8 \%$, respectively, in winter (ERCOT 2017a, b). ERCOT's assessments assume that fossil and hydropower resources are fully available to supply peak demand in both seasons.
Tables 1 and 2 show each site's specific PACP for the summer and winter, respectively. The solar sites had PACPs of $66 \%$ during summertime peak hours and $11 \%$ during wintertime peak hours. This is roughly in line with the fact that ERCOT applies factors of $75 \%$ in summer and $9.8 \%$ in winter in its resource adequacy assessments (ERCOT 2018). At individual sites, 2007-2013 average summertime PACP varied from 58.4 to $68.3 \%$, while the interannual range was $12.0-23.5$ percentage points. In winter, sites achieved 2007-2013 average PACP of 9.4$13.3 \%$ and interannual ranges of $11.2-26.8$ percentage points.

For the three WT wind sites, we computed PACP to average $19 \%$ in summertime peak hours and $42 \%$ in wintertime peak hours. Note that these levels are substantially higher than the $14 \%$ and $20 \%$ factors applied by ERCOT in its resource adequacy assessments (ERCOT $2017 \mathrm{a}, \mathrm{b})$. PACP ranged from 14.7 to $25.2 \%$ across individual sites in the summer, and from 32.4 to $50.0 \%$ in winter. For the selected ST wind sites, we find PACPs to average $38 \%$ in summer and $48 \%$ in winter, compared to ERCOT's $59 \%$ and $42 \%$ for summer and winter, respectively. This raises concerns about the seasonality assumed by ERCOT for ST wind sites.

We next examine the monthly and diurnal cycles of power production for each site. Interannual ranges and averages of capacity factors, averaged over each of the three resource types, are shown in Fig. 3. The monthly capacity factors of the highest production WT wind, ST wind, and solar sites for years 2007-2013 are plotted in Fig. 4 and show the general spread of possible production

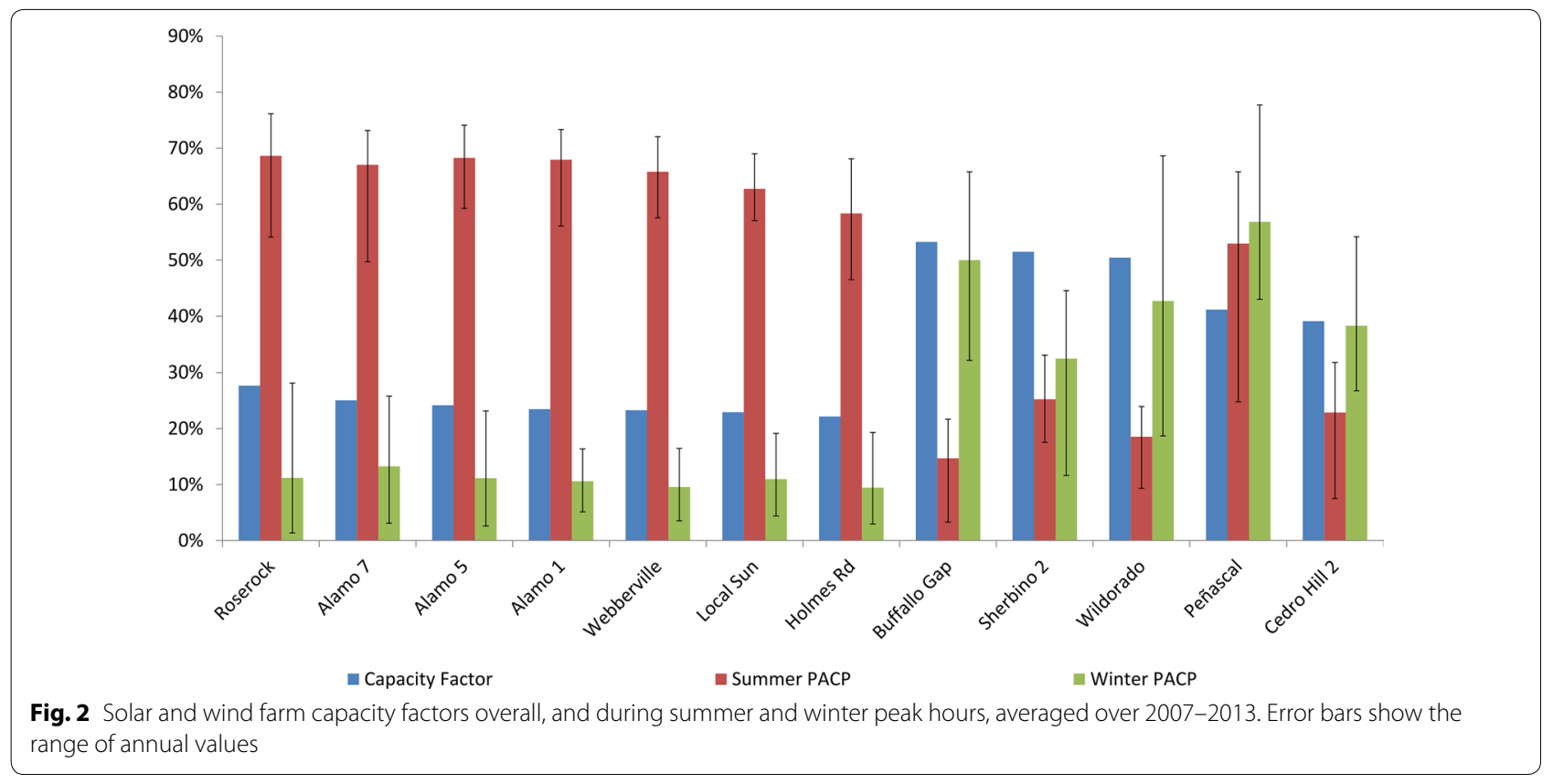


Table 1 Peak average capacity percentages for each solar and wind site during each summer

\begin{tabular}{|c|c|c|c|c|c|c|c|c|}
\hline Site & S2007 (\%) & S2008 (\%) & S2009 (\%) & S2010 (\%) & S2011 (\%) & S2012 (\%) & S2013 (\%) & Average (\%) \\
\hline \multicolumn{9}{|l|}{ SOLAR } \\
\hline Alamo 1 & 62.6 & 56.1 & 68.3 & 73.2 & 73.3 & 69.2 & 72.6 & 67.9 \\
\hline Alamo 5 & 61.9 & 59.2 & 71.6 & 74.0 & 74.1 & 66.8 & 70.2 & 68.3 \\
\hline Alamo 7 & 73.2 & 49.7 & 69.4 & 69.6 & 69.6 & 69.8 & 67.9 & 67.0 \\
\hline Holmes Rd & 53.7 & 57.5 & 55.5 & 46.5 & 68.1 & 60.3 & 66.8 & 58.4 \\
\hline Local Sun & 57.7 & 57.0 & 65.7 & 61.5 & 66.7 & 61.4 & 69.0 & 62.7 \\
\hline Roserock & 70.5 & 63.1 & 71.9 & 73.1 & 76.1 & 71.5 & 54.1 & 68.6 \\
\hline Webberville & 59.0 & 57.6 & 69.8 & 66.4 & 72.0 & 64.3 & 71.4 & 65.8 \\
\hline \multicolumn{9}{|l|}{ W-TXWIND } \\
\hline Buffalo Gap & 16.8 & 21.7 & 17.5 & 3.3 & 11.4 & 17.4 & 14.8 & 14.7 \\
\hline Sherbino 2 & 17.6 & 25.5 & 33.1 & 20.3 & 24.8 & 29.4 & 26.0 & 25.2 \\
\hline Wildorado & 18.6 & 18.3 & 23.7 & 9.3 & 20.1 & 15.8 & 23.9 & 18.5 \\
\hline \multicolumn{9}{|l|}{ S-TXWIND } \\
\hline Cedro Hill 2 & 31.7 & 25.6 & 26.7 & 7.5 & 19.3 & 24.2 & 24.9 & 22.9 \\
\hline Peñascal & 46.2 & 60.7 & 65.8 & 24.8 & 55.9 & 53.7 & 63.6 & 53.0 \\
\hline
\end{tabular}

Table 2 Peak average capacity percentages for each solar and wind site during each winter

\begin{tabular}{|c|c|c|c|c|c|c|c|}
\hline Site & W2007-8 (\%) & W2008-9 (\%) & W2009-10 (\%) & W2010-11 (\%) & W2011-12 (\%) & W2012-13 (\%) & Average (\%) \\
\hline \multicolumn{8}{|l|}{ SOLAR } \\
\hline Alamo 1 & 8.1 & 10.1 & 16.4 & 5.1 & 11.5 & 12.4 & 10.6 \\
\hline Alamo 5 & 9.5 & 10.7 & 14.7 & 6.1 & 2.6 & 23.1 & 11.1 \\
\hline Alamo 7 & 10.1 & 14.4 & 25.8 & 9.0 & 3.1 & 17.1 & 13.3 \\
\hline Holmes Rd & 10.5 & 9.9 & 19.3 & 3.0 & 4.4 & 9.6 & 9.4 \\
\hline Local Sun & 8.4 & 15.0 & 19.2 & 9.0 & 4.4 & 9.8 & 11.0 \\
\hline Roserock & 4.2 & 14.3 & 13.4 & 5.7 & 1.3 & 28.1 & 11.2 \\
\hline Webberville & 7.9 & 16.4 & 12.8 & 5.8 & 3.5 & 10.9 & 9.6 \\
\hline \multicolumn{8}{|l|}{ W-TX WIND } \\
\hline Buffalo Gap & 43.7 & 32.1 & 50.4 & 65.8 & 59.5 & 48.6 & 50.0 \\
\hline Sherbino 2 & 44.6 & 29.9 & 11.6 & 42.3 & 35.0 & 31.0 & 32.4 \\
\hline Wildorado & 66.8 & 52.8 & 25.3 & 24.1 & 68.6 & 18.7 & 42.7 \\
\hline \multicolumn{8}{|l|}{ S-TXWIND } \\
\hline Cedro Hill 2 & 27.1 & 26.7 & 45.0 & 49.5 & 27.1 & 54.2 & 38.3 \\
\hline Peñascal & 45.9 & 43.5 & 72.4 & 77.7 & 43.0 & 58.5 & 56.8 \\
\hline
\end{tabular}

values and the interannual variability of resource availability at these representative locations. Notably, interannual variability of solar production is greatest in the summer, whereas ST wind is variable in summer and winter and WT wind is most variable in spring and autumn.

To assess resource complementarity over the course of a day, aggregate half-hourly production values for each resource were compared for two model days: June 21 (summer solstice) and December 21 (winter solstice) (Fig. 5). The average capacity factor each half-hour over years 2007-2013 is shown in Fig. 5. On June 21, WT wind and solar resources exhibited complementary production patterns over the course of the day, with solar production peaking in the daytime hours and WT wind production peaking at night. ST wind production peaked in the late evening, between the solar and WT wind peak production times, and remained lower than WT wind production for the duration of the day. On December 21, ST wind and solar production values were lower than their summertime levels, while WT wind showed a flatter diurnal profile during winter than in summer.

The three categories of sites exhibit starkly different diurnal patterns in output. At the WT wind sites, output peaks late at night, around 23:30 CST. By contrast, output from the solar sites peaks just after noon, when the WT 


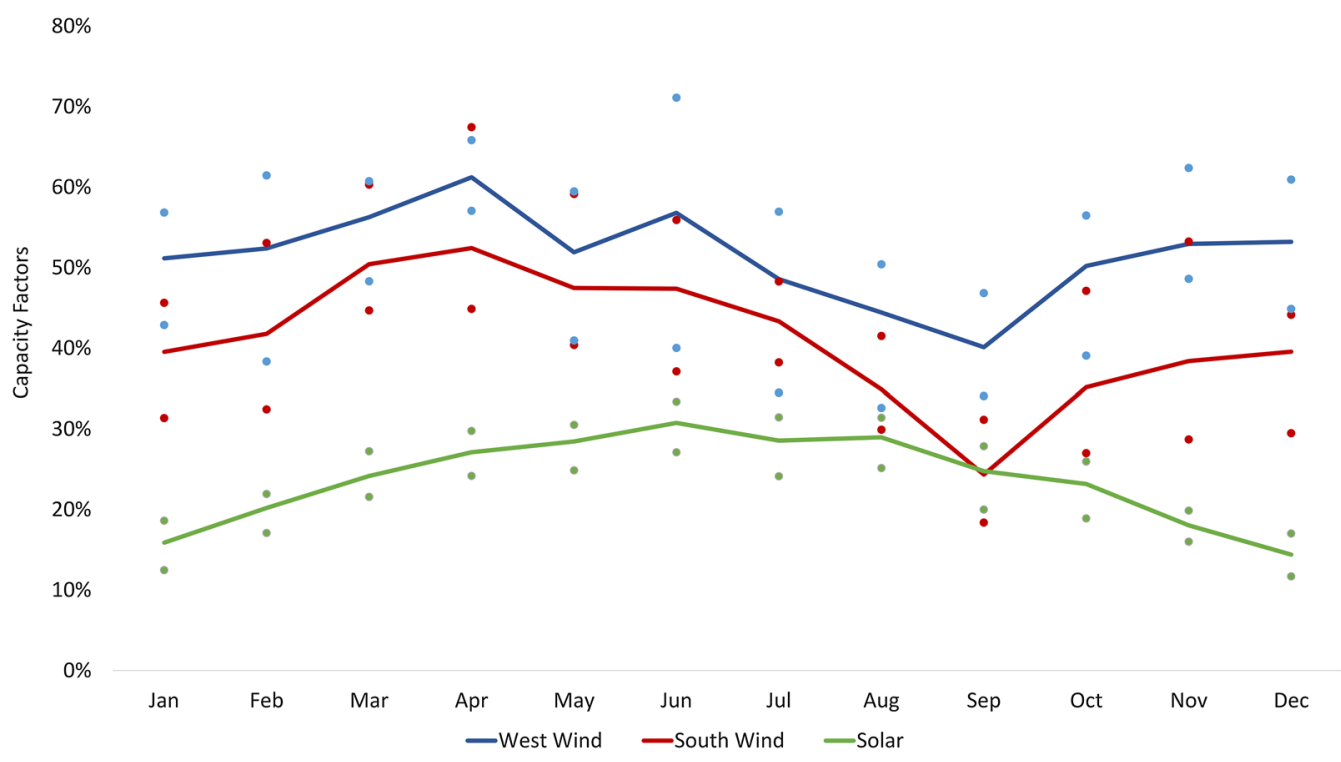

Fig. 3 Average monthly capacity factors for each resource type over the years 2007-2013. Circles display interannual minima and maxima

wind sites are near their daily lows. Meanwhile, output from ST wind sites peaks in late afternoon, around 16:00 $\mathrm{CST}$, and is lowest early in the morning.

\section{Paired site analyses}

While the contrasting temporal patterns described above for individual sites are suggestive of complementarity, paired site analyses allow for complementarity to be probed more directly. One indicator of complementarity of two sites is whether their output is inversely correlated over time, allowing one site to produce more power when the other is unavailable. Table 3 shows the Pearson correlation coefficient for each pair of sites. As expected, pairs of solar sites were strongly correlated, with correlation coefficients ranging from 0.81 to 0.92 . Pairs of wind sites were less strongly correlated. In particular, pairing a WT and a ST wind site led to correlation coefficients of just 0.11-0.37 (Table 3). Pairs of WT wind sites had correlation coefficients of $0.44-0.53$, and the two ST wind sites had a correlation of 0.75 (Table 3 ). The lower correlation coefficients across regions illustrate the value of siting wind farms in different parts of the state.

Even better complementarity can be achieved by pairing wind with solar, as each of these pairings had negative correlation coefficients. The average correlation between solar sites and wind sites was -0.287 , suggesting a weak inverse relationship between solar production and wind production. In particular, solar was more inversely correlated with the WT wind sites $(-0.31$ to
$-0.37)$ than with the most coastal of the ST wind sites, Peñascal $(-0.12$ to -0.15$)$. Cedro Hill 2 had an intermediate level of inverse correlation with solar.

As explained by Archer and Jacobson (2007), firm capacity provides an additional metric of complementarity by illustrating the minimum amount of power that can be guaranteed for a given percentile of hours per year. We assessed the firm capacity of each pair of sites and illustrate it in Fig. 6 for the pair of sites (Roserock solar and Buffalo Gap wind) that had the greatest firm capacity in 2012 at the 87.5 percentile level considered by Archer and Jacobson (2007). The power duration curves in Fig. 6 are plotted for each site individually and taken together as a pair (in each case with total capacity assumed to be $60 \mathrm{MW}$ ), and the vertical line represents the $87.5 \%$ threshold. The combination of Roserock solar and Buffalo Gap wind power would output at least $13.2 \%$ of its capacity for $87.5 \%$ of the hours of the year. By contrast, solar alone has zero firm capacity at this threshold, since it is dark half the time. The Buffalo Gap wind site alone has a firm capacity factor of just $4 \%$ at the $87.5 \%$ threshold.

The highest and lowest ten firm capacities determined for single and paired sites are shown in Table 4. We exclude the solar-solar pairs, which inherently provide zero firm capacity. The highest firm capacities were exhibited by solar and WT wind pairs (specifically with pairs that included the Buffalo Gap wind site) and by WT and ST wind site pairs. Conversely, solar and ST wind pairings and single wind sites produced lower firm capacities, since these sites have both 

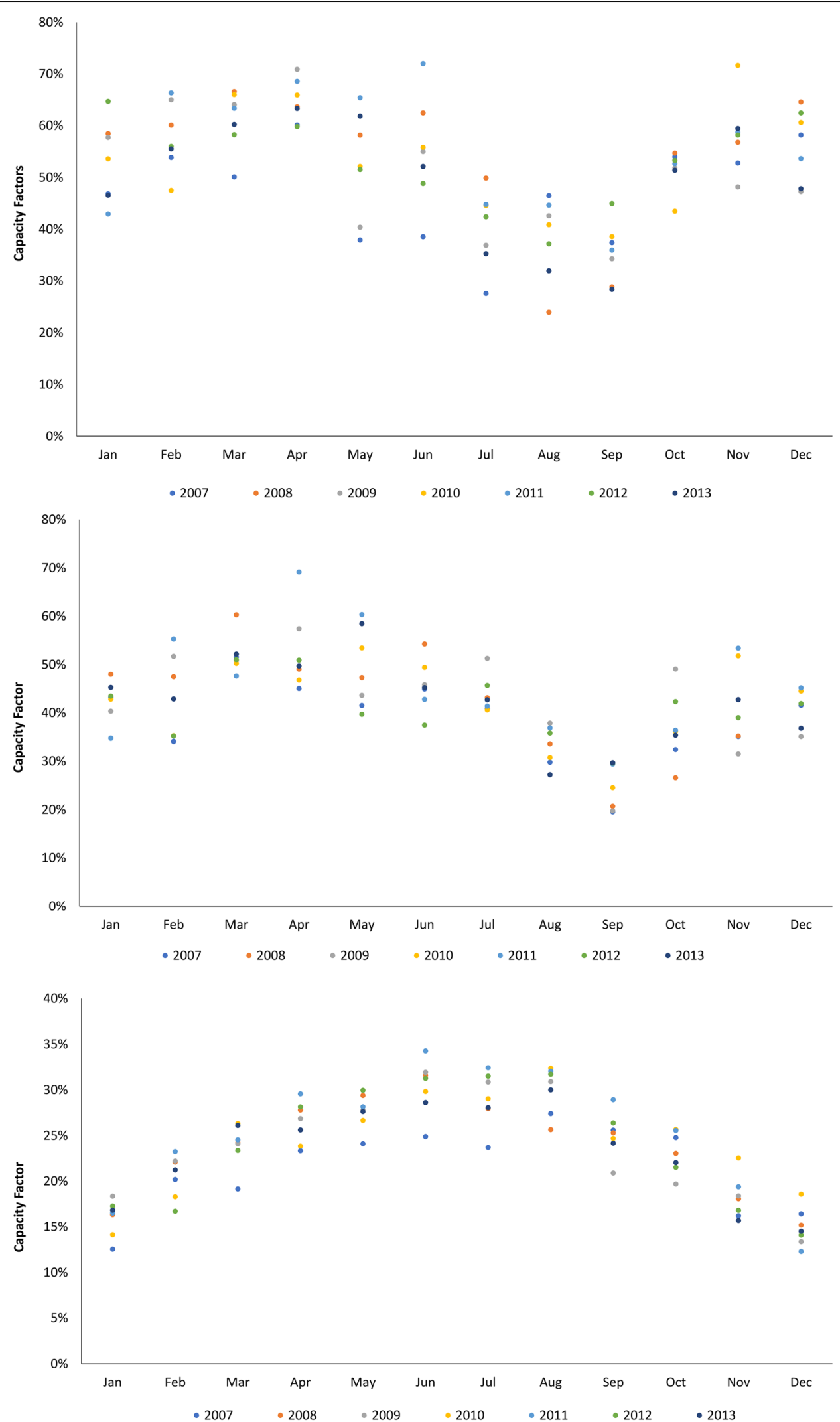

Fig. 4 Monthly capacity factors for representative sites for Buffalo Gap (WT wind, top), Peñascal (ST wind, middle), and Alamo 5 (solar, bottom) 
1

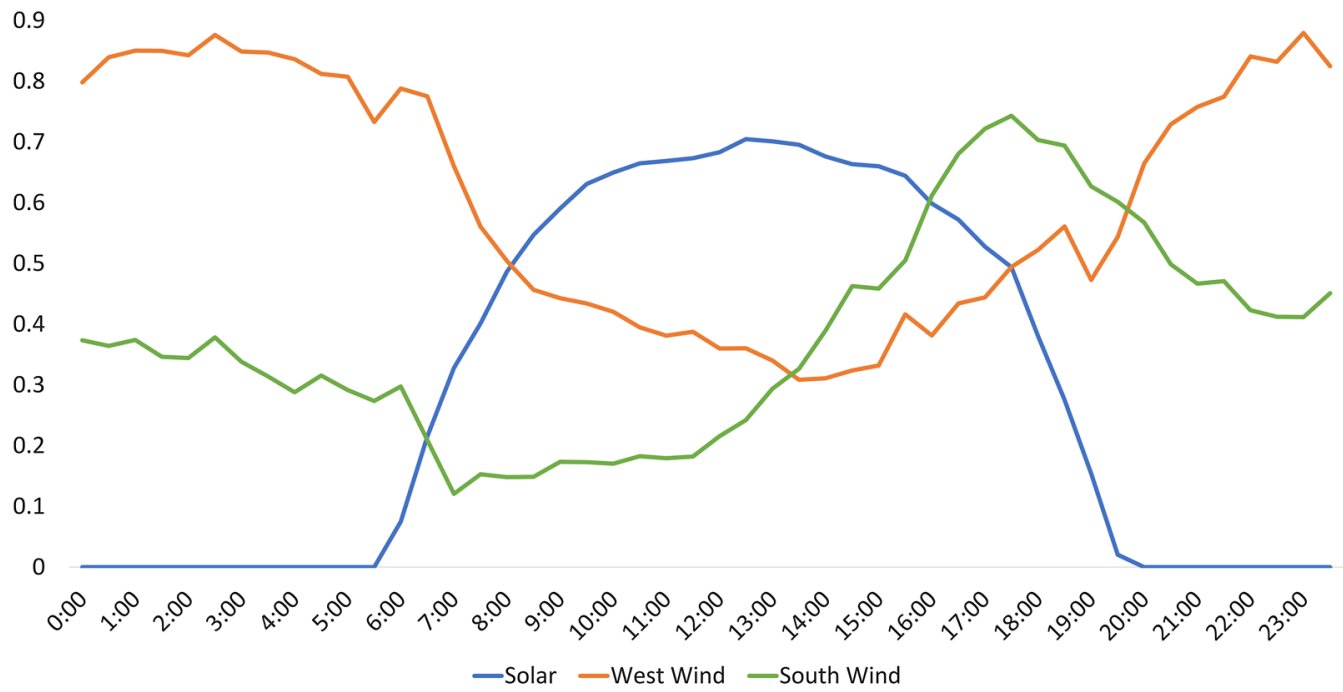

0.8

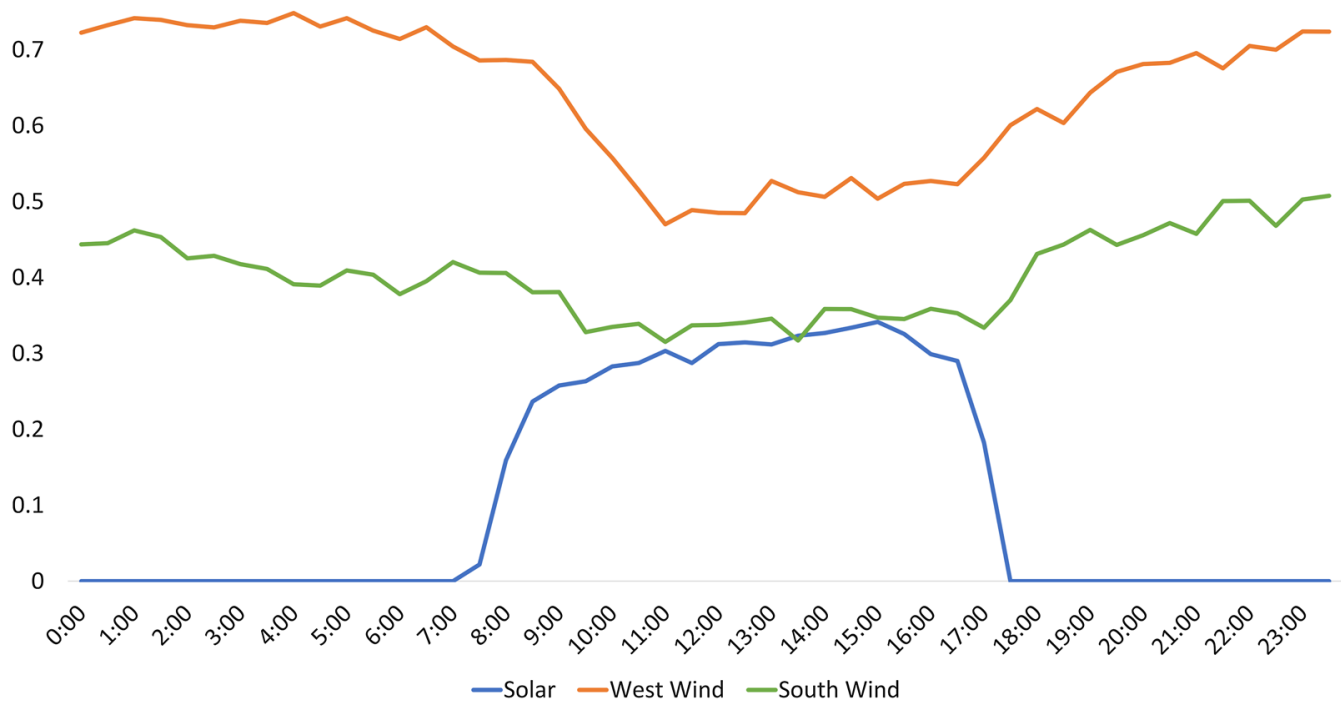

- Solar - West Wind —South Wind

Fig. 5 Half-hour average capacity factor for each site, 2007-2013, on June 21 (top) and December 21 (bottom)

lower capacity factors overall and less negative inverse correlations.

\section{Solar configuration options}

All of the analyses above assume single-axis tracking, the most widely used option for utility-scale solar farms. However, it is possible that a mix of alignments could prove complementary or that west-facing arrays could provide power during summer afternoon peak loads. To test how changes in solar array configuration might effect production and complementarity, five solar configurations were considered: fixed-tilt systems with tilt equivalent to latitude pointed south (S), southwest (SW), and west (W); single-axis tracking from west to east; and dual-axis tracking. The highest production solar site, Roserock, was used as the model site in all of the following analyses, and the highest production wind site (Buffalo Gap) was used to measure changes in complementarity between WT wind and solar as the solar array configurations changed.

Production achieved by the different array configurations was measured using capacity factor and PACP (Fig. 7). As expected, capacity factor was largest for the tracking configurations and lowest for the fixed-tilt 


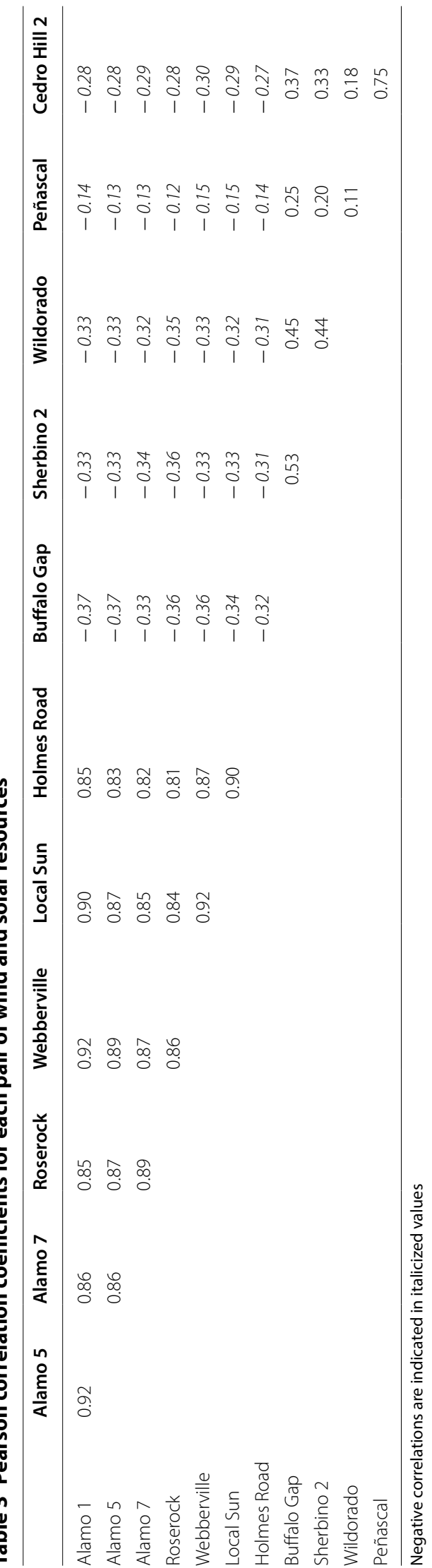




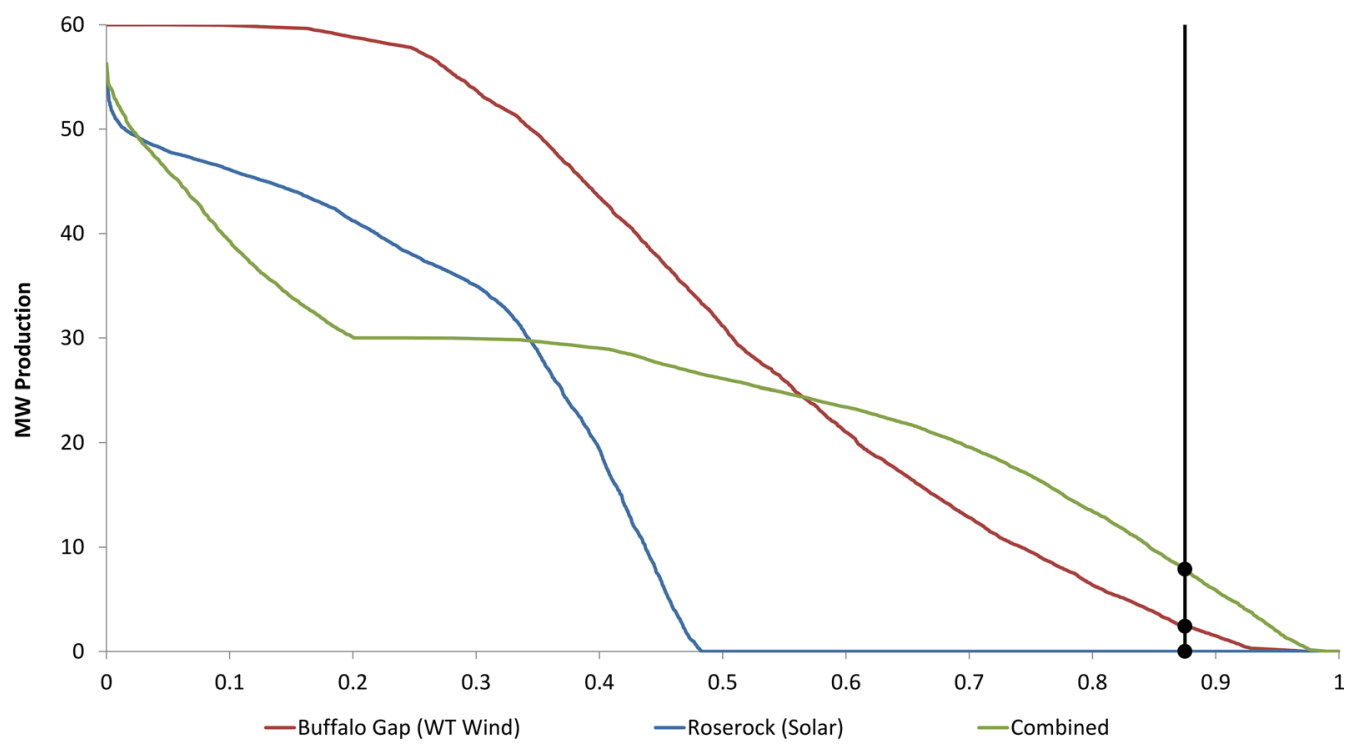

Fig. 6 Duration curves of Roserock solar and Buffalo Gap wind sites' separate and combined hourly power production and firm capacity (out of $60 \mathrm{MW}$ total capacity) at an $87.5 \%$ availability threshold

Table 4 Pairs of sites with the ten highest and ten lowest firm capacities, defined here as the amount of capacity (out of $60 \mathrm{MW}$ ) available at least $87.5 \%$ of the time

\begin{tabular}{|c|c|c|}
\hline Site 1 & Site 2 & $\begin{array}{l}\text { Firm } \\
\text { capacity } \\
\text { (MW) }\end{array}$ \\
\hline \multicolumn{3}{|c|}{ Ten greatest firm capacities } \\
\hline Roserock (So) & Buffalo Gap (WT w) & 7.92 \\
\hline Roserock (So) & Sherbino 2 (WT w) & 7.55 \\
\hline Peñascal (ST w) & Sherbino 2 (WT w) & 7.44 \\
\hline Peñascal (ST w) & Wildorado (WT w) & 7.31 \\
\hline Peñascal (ST w) & Buffalo Gap (WT w) & 7.17 \\
\hline Alamo 5 (So) & Buffalo Gap (WT w) & 7.08 \\
\hline Alamo 7 (So) & Buffalo Gap (WT w) & 7.04 \\
\hline Alamo 1 (So) & Buffalo Gap (WT w) & 6.99 \\
\hline Alamo 7 (So) & Sherbino 2 (WT w) & 6.98 \\
\hline Webberville (So) & Buffalo Gap (WT w) & 6.88 \\
\hline \multicolumn{3}{|c|}{ Ten lowest firm capacities } \\
\hline Holmes Rd (So) & Cedro Hill 2 (ST w) & 4.65 \\
\hline Alamo 1 (So) & Peñascal (ST w) & 4.63 \\
\hline Webberville (So) & Peñascal (ST w) & 4.63 \\
\hline Holmes Rd (So) & Peñascal (ST w) & 4.45 \\
\hline Cedro Hill 2 (ST w) & Peñascal (ST w) & 2.88 \\
\hline Sherbino 2 (WT w) & & 2.77 \\
\hline Buffalo Gap (WT w) & & 2.42 \\
\hline Wildorado (WT w) & & 1.62 \\
\hline Cedro Hill 2 (ST w) & & 1.59 \\
\hline Peñascal (ST w) & & 1.31 \\
\hline
\end{tabular}

Not shown are pairs of solar-only sites, which have firm capacity of zero systems. Additionally, both summer and winter PACPs were higher for dual-axis tracking and single-axis tracking systems, respectively. For fixed-tilt systems, summer PACP rose and winter PACP fell as the system moved from south-facing to west-facing. Overall, the west-facing fixed-tilt system has the lowest total capacity factor of $18 \%$, compared to $32 \%$ for the dual-axis tracking system; however, in the summer during peak load hours, the west-facing fixed-tilt system had a PACP of $72 \%$, nearly as high as the $74 \%$ for dual-axis tracking. Single-axis tracking costs about $\$ 0.15 / \mathrm{W}_{\mathrm{AC}}$ more than fixed systems (Bolinger et al. 2017), and dual-axis tracking systems are rarely deployed. Thus, the ability of west-facing fixed-tilt systems to achieve such high summertime PACP can be relevant in certain circumstances.

Next, to measure potential complementarity between solar configurations, correlation coefficients were calculated between half-hourly production for the five array types as well as the Buffalo Gap WT wind location (Table 5). Single-axis tracking followed by the west-facing fixed-tilt array yielded the most strongly negative correlation coefficients with Buffalo Gap, but the differences across the solar configurations were small. The greatest complementarity between two solar array types at the Roserock location was achieved by the west-facing fixedtilt system combined with the dual-axis tracking system. Pairing a west-facing and south-facing fixed-tilt system also yielded a relatively low correlation coefficient and hence better complementarity than other pairings.

Effects of array type on reliable combined production with a WT wind farm were measured with firm capacity 


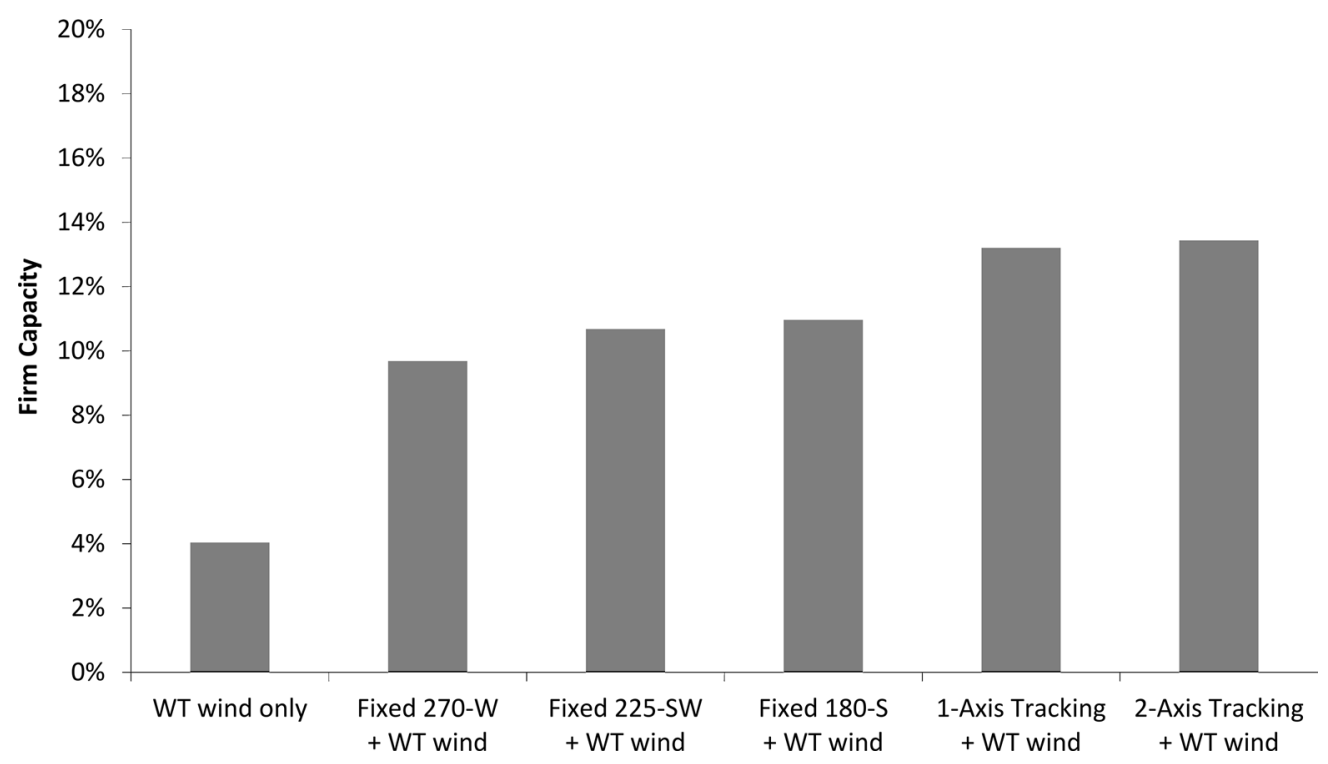

Fig. 7 Capacity factors of various configurations of solar arrays at Roserock for 2012 overall, and during peak load hours of summer and winter

Table 5 Pearson correlation coefficients of half-hourly production between the Buffalo Gap wind site (right column) and five potential configurations of a Roserock solar plant

\begin{tabular}{llllll}
\hline & 2-Tracking & Fixed S & Fixed SW & Fixed W & Wind \\
\hline 1-Tracking & \multirow{2}{0.988}{} & 0.90 & 0.86 & 0.82 & -0.36 \\
2-Tracking & & 0.92 & 0.88 & 0.81 & -0.34 \\
Fixed S & & & 0.93 & 0.82 & -0.32 \\
Fixed SW & & & & 0.96 & -0.34 \\
Fixed W & & & & & -0.35 \\
\hline
\end{tabular}

Negative correlations are highlighted in italicized values

(Fig. 8). WT wind alone had the least firm capacity, followed by similar capacity factors for all fixed-tilt systems combined with wind, leaving both single- and dual-axis tracking with similar firm capacities combined with WT wind. The firm capacity percentages followed a similar trend to the farms' individual capacity factors, suggesting that the differences among solar configurations in complementarity with wind are negligible.

\section{Conclusions}

West Texas wind produced the most total power annually, followed by South Texas wind production and then solar. Over the year, solar production is complementary with both WT and ST wind. WT wind paired with solar provided the highest levels of firm capacity at an $87.5 \%$ threshold. Accordingly, combining solar resources with WT wind might increase reliable power production on an annual basis. On a daily basis, however, WT wind,
ST wind and solar all have different peak production times with ST wind peaking in the later afternoon, when demand for power is highest. This suggests that combining solar with ST wind might increase reliable power production over the course of a summer day during hours of high demand.

Directly comparing the sites' hourly production with times of greatest demand throughout the year yielded further insights. Solar production was the highest during summer hours when load on the ERCOT grid was highest, and WT and ST wind productions were the highest during winter peak hours. WT wind showed greater production during both the summer and winter peak hours than the ERCOT estimate, suggesting ERCOT's approach is conservative in this case. Our results also suggest a need for ERCOT to re-evaluate its estimates of ST wind availability during seasonal peak hours. We estimate that these coastal sites provide more output during winter peak load than summer, contrary to ERCOT's assumptions in its resource assessments.

Comparisons of different solar configurations show that, though a west-facing fixed-tilt system yields less than half the output of a dual-axis tracking system, it can produce almost as much power during the peak load hours for summer. This suggests that a relatively low-cost system could play a valuable role in meeting summer peak demand.

Areas for further investigation include expanding the scope of measurements from seven sample sites to locations throughout the state in order to pinpoint specific locations that maximize complementarity (thus 


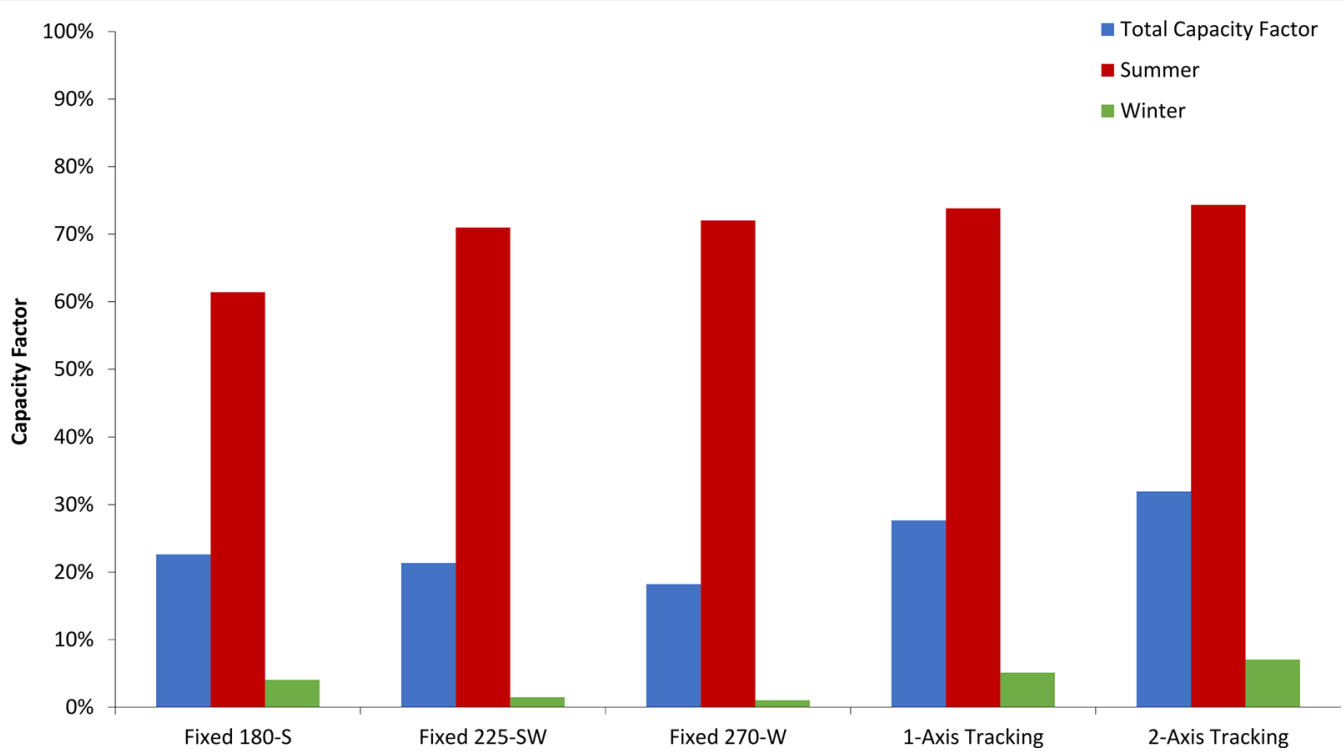

Fig. 8 Firm capacities at $87.5 \%$ for the $60 \mathrm{MW}$ combined farms for WT wind site Buffalo Gap and various solar array configurations at the Roserock solar site. This metric shows the change in guaranteed production for WT wind and solar sites with different configurations

reliability) and best meet demand over the course of each day. Further research could also explore alternatives to the ERCOT resource adequacy factors that might more fully characterize the reliable production potential of Texas renewables. These results might suggest ways to organize future renewables projects to maximize reliability with minimal investment in expensive storage technologies. Such analyses will become increasingly important as the mix of Texas variable renewable electricity supply shifts from predominately West Texas wind to include more solar power and a broader mix of wind locations.

\section{Abbreviations}

ERCOT: Electric Reliability Council of Texas; GHI: global horizontal irradiance; GOES: Geostationary Operational Environmental Satellites; NREL: National Renewable Energy Lab; NSRDB: National Solar Radiation Database; PACP: peak average capacity percentage; PSM: Physical Solar Model; SAM: System Advisor Model; WIND: Wind Integration National Dataset.

\section{Authors' contributions}

JS conducted the modeling and analysis and wrote the initial draft of the paper. DC developed the ideas to be studied, mentored the research, and revised the paper. Both authors read and approved the final manuscript.

\section{Acknowledgements}

Special acknowledgement goes to Caleb Phillips from the National Renewable Energy Laboratory for providing access to Texas-wide wind and solar data for 2013 from NREL's open source datasets.

\section{Competing interests}

The authors declare no competing interests.

\section{Availability of data}

Upon acceptance of the article, we will share all relevant input and output data via the Open Science Framework (osf.io) or other data repository.

\section{Funding}

No external funding was received for this work.

\section{Publishers Note}

Springer Nature remains neutral with regard to jurisdictional claims in published maps and institutional affiliations.

Received: 6 September 2018 Accepted: 8 November 2018

Published online: 16 November 2018

\section{References}

Archer, C. L., \& Jacobson, M. Z. (2007). Supplying baseload power and reducing transmission requirements by interconnecting wind farms. Journal of Applied Meteorology and Climatology, 46, 1701-1717. https://doi. org/10.1175/2007jamc1538.1.

Bolinger, M., Seel, J., \& LaCommare, K. (2017). Utility-scale solar 2016: An empirical analysis of project cost, performance, and pricing trends in the United States. Electricity Markets and Policy Group, LBNL-2001055.

Draxl, C., Clifton, A., Hodge, B., \& McCaa, J. (2015). The Wind Integration National Dataset (WIND) Toolkit. Applied Energy, 151, 355-366.

ERCOT. (2017a). Inside the Promise. 2016 State of the Market Report, Energy Reliability Council of Texas (ERCOT), Austin, http://www.ercot.com/content/ wcm/lists/114739/ERCOT_Quick_Facts_10917.pdf. Accessed 4 Nov 2018.

ERCOT. (2017b). Seasonal Assessment of Resource Adequacy for the ERCOT Region [Microsoft Excel spreadsheet]. Winter 2017-18 Final Seasonal Assessment, Energy Reliability Council of Texas (ERCOT). Retrieved from: http://www. ercot.com/gridinfo/resource. Accessed 4 Nov 2018.

ERCOT. (2018). Seasonal Assessment of Resource Adequacy for the ERCOT Region [Microsoft Excel spreadsheet]. Summer 2018 Preliminary Seasonal Assessment, Energy Reliability Council of Texas (ERCOT). Retrieved from: http:// www.ercot.com/gridinfo/resource. Accessed 4 Nov 2018.

Hart, E. K., Stoutenburg, E. D., \& Jacobson, M. Z. (2012). The Potential of intermittent renewables to meet electric power demand: Current methods and emerging analytical techniques. Proceedings of the IEEE, 100, 322-334. https://doi.org/10.1109/jproc.2011.2144951. 
Jacobson, M. Z. (2008). Review of solutions to global warming, air pollution, and energy security. Energy and Environmental Science, 2, 148-173. https ://doi.org/10.1039/b809990c.

Kahn, E. (1979). The reliability of distributed wind generators. Electric Power Systems Research, 2(1), 1-14.

Katzenstein, W., Fertig, E., \& Apt, J. (2010). The variability of interconnected wind plants. Energy Policy, 38, 4400-4410. https://doi.org/10.1016/j.enpol 2010.03.069.

Lazard. (2017). Levelized Cost of Energy 2017. Lazard's Levelized Cost of Energy Analysis. www.lazard.com/perspective/levelized-cost-of-energy-2017/. Accessed 4 Nov 2018

Liu, Y., Xiao, L.Y., Wang, H.F., Dai, S.T., \& Qi, Z.P. (2013). Analysis on the hourly spatiotemporal complementarities between China's solar and wind energy resources spreading in a wide area. Science China Technological Sciences, 56(3), 683-692. https://doi.org/10.1007/s11431-012-5105-1.

Monfortia, F., Hulda, T., Bódisa, K., Vitalic, L., D'Isidoroc, M., \& Lacal-Arántegui, R. (2014). Assessing complementarity of wind and solar resources for energy production in Italy. A Monte Carlo approach. Renewable Energy, 63, 576-586. https://doi.org/10.1016/j.renene.2013.10.028.
Prasad, A. A., Taylor, R. A., \& Kay, M. (2007). Assessment of solar and wind resource synergy in Australia. Applied Energy, 190, 354-367. https://doi. org/10.1016/j.apenergy.2016.12.135.

Sengupta, M., Weekley, A., Habte, A., Lopez, A., Molling, C., \& Heidinger, A. (2015). Validation of the National Solar Radiation Database (NSRDB) (2005-2012): Preprint. National Renewable Energy Lab, 6, NREL/ CP-5D00-64981.

Shaner, M. R., Davis, S. J., Lewis, N. S., \& Caldeira, K. (2018). Geophysical Constraints on the Reliability of Solar and Wind Power in the United States. Energy and Environmental Science. https://doi.org/10.1039/c7ee03029k.

Yang, D. (2018a). A correct validation of the National Solar Radiation Data Base (NSRDB). Renewable and Sustainable Energy Reviews, 97, 152-155.

Yang, D. (2018b). Kriging for NSRDB PSM version 3 satellite-derived solar irradiance. Solar Energy, 171, 876-883.

Zhou, W., Lou, C., Li, Z., Lu, L., \& Yang, H. (2010). Current status of research on optimum sizing of stand-alone hybrid solar-wind power generation systems. Applied Energy, 87, 380-389.

\section{Submit your manuscript to a SpringerOpen ${ }^{\circ}$ journal and benefit from:}

- Convenient online submission

- Rigorous peer review

- Open access: articles freely available online

- High visibility within the field

- Retaining the copyright to your article

Submit your next manuscript at $\boldsymbol{\nabla}$ springeropen.com 